\title{
Mounier Kuhn Syndrome: A Rare Variety of Bronchial Dilatation
}

Fatima Zahra Mrabet*, Jihane Achrane, Hicham Souhi, Hanane Ouazzani, Ismail Rhorfi and Ahmed Abid Department of Pulmonology, Mohamed V Military Training Hospital, Morocco

Submission: April 16, 2019; Published: July 15, 2019

*Corresponding author: Fatima Zahra Mrabet, Department of Pulmonology, Mohamed V Military Training Hospital, Rabat, Morocco

\section{Abstract}

Background: Mounier Kuhn's syndrome is a rare condition. It is characterised by an increase in the diameter of the trachea and main bronchi. Imaging plays a fundamental role in confirming the diagnosis. This syndrome is little known and has not benefit of enough studies allowing a better comprehension of its pathophysiology and a performing therapeutic approach.

Case presentation: In this paper, we report the case of a 53-year-old man suffering from recurrent respiratory infections. Imaging has made the diagnosis of Mounier Kuhn syndrome by showing an increase in the diameter of the trachea and main bronchi. The treatment was based on physiotherapy and appropriate antibiotic therapy in case of infectious outbreak.

Conclusions: This long-neglected "orphan disease" should receive more research attention in order to provide better understanding of its aetiology, pathogenesis and multimodality treatment.

Keywords: Mounier Kuhn Syndrome; Tracheal Dilatation; Bronchial Dilatation; Congenital and Rare Disease; Radiological Diagnosis

Abbreviations: CT: Computed Tomography; MRI: Magnetic Resonance Imaging

\section{Background}

Mounier Kuhn's syndrome is a rare and congenital disease. It is characterized by an increase in the size of the trachea and main bronchi caused by a congenital disorder of the connective tissue and smooth muscles of these structures, the distal bronchial tree is usually normal. Its diagnosis is accomplished with the Case Report use of Computed Tomography (CT). It can be associated with other congenital conditions, which makes the understanding of its physiopathology more complicated. Its clinical features vary from being asymptomatic to severe respiratory distress. However, therapy remains conservative [1].

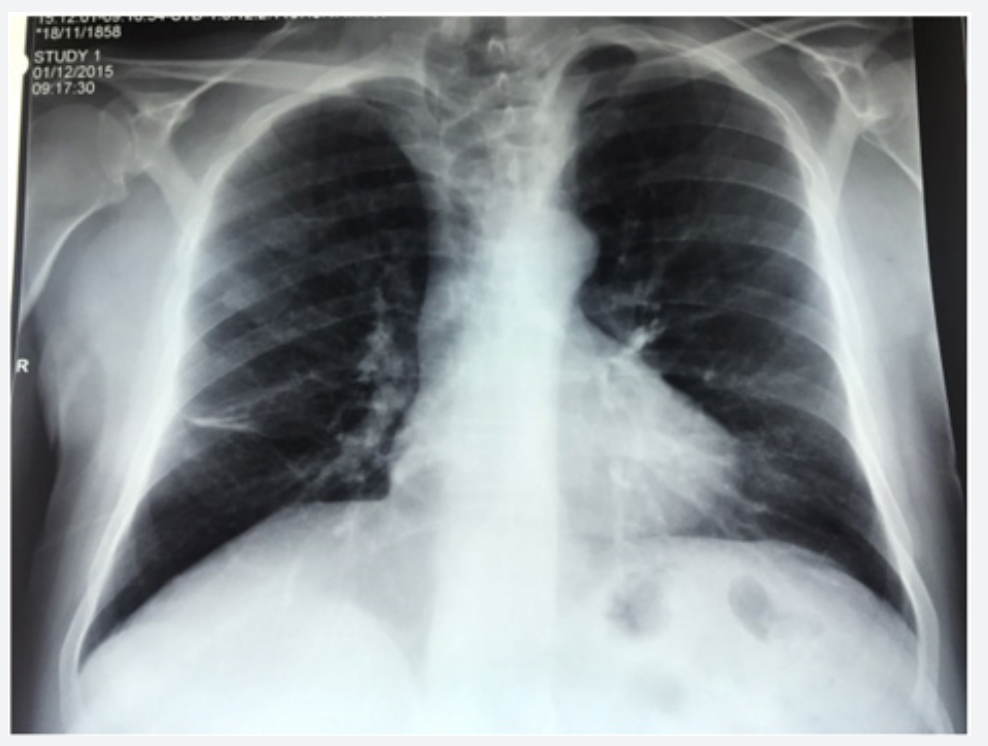

Figure 1: Chest $\mathrm{X}$-ray showing tracheal dilatation. 


\section{International Journal of Pulmonary \& Respiratory Sciences}

$\mathrm{Mr} \mathrm{AB}$, a 53 years old non-smoking patient and father of 7 children, with a history of recurrent respiratory infections. He was admitted for a cough and purulent sputum evolving in a context of deterioration of the general state. Clinical examination showed bilateral ptosis, polypnea at 22 breathes per minute, sonorous bilateral rales in pleuro-pulmonary auscultation and a fever at $38.5^{\circ} \mathrm{C}$. Chest X-ray showed tracheal dilation (Figure 1).
Blood tests found a CRP at $75 \mathrm{mg} / \mathrm{l}$, white blood cells at $12,500 / \mathrm{mm}^{3}$ predominantly of neutrophils at full blood count. Thoracic computed tomography was conducted (Figures 2-4) and revealed tracheal dilation with a diameter of $35 \mathrm{~mm}$ (whereas the normal diameter should not exceed $25 \mathrm{~mm}$ in humans), and dilation of main stem bronchi with a diameter of $25 \mathrm{~mm}$ on the right and $26 \mathrm{~mm}$ on the left.

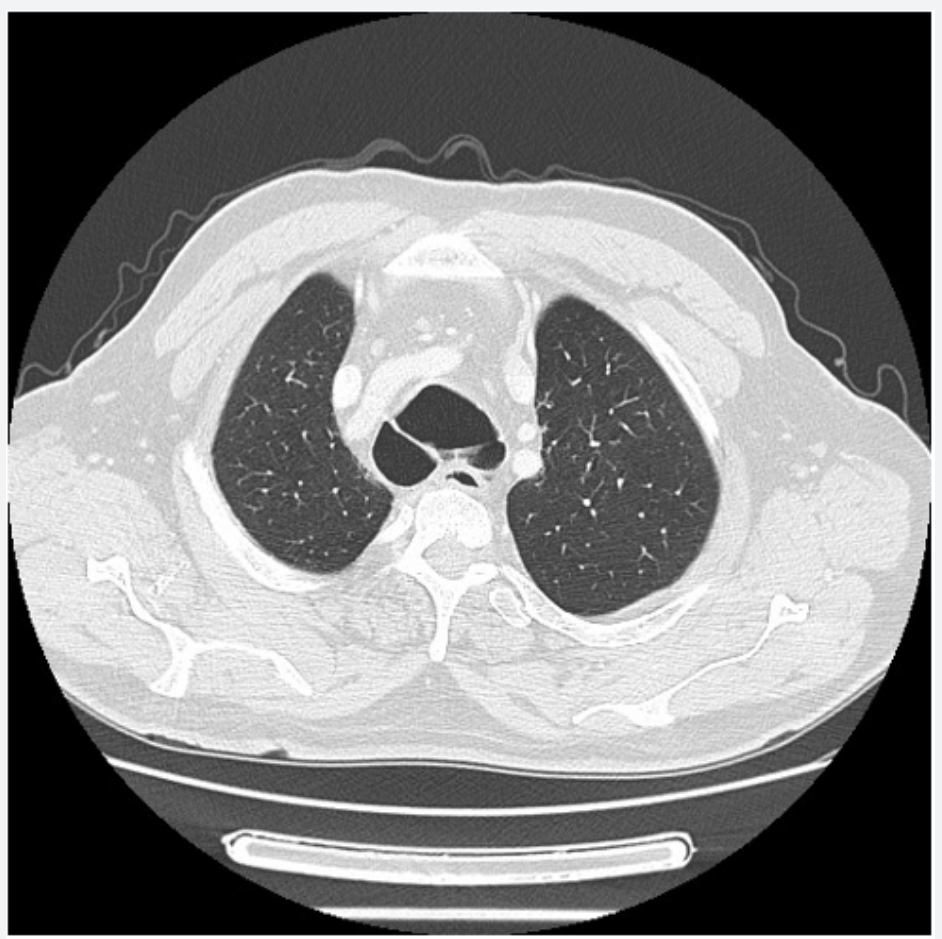

Figure 2: CT scan showing tracheal dilatation.

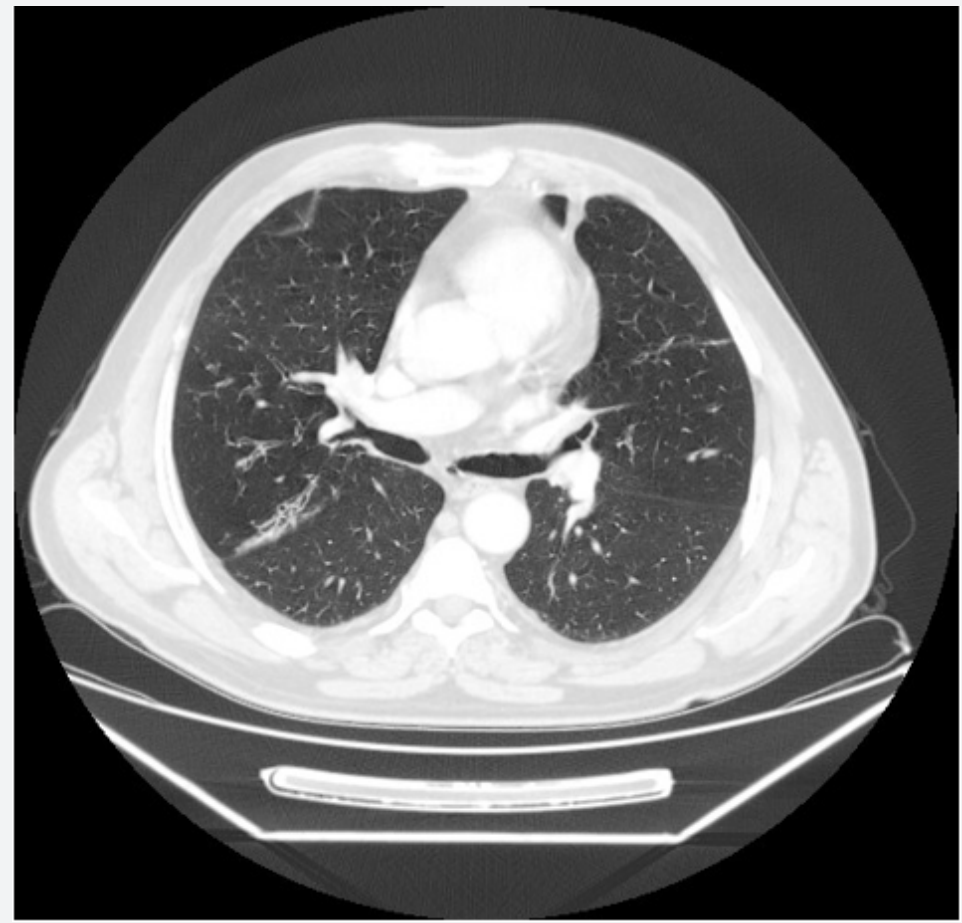

Figure 3: CT scan showing an increase in the diameter of both main bronchi. 


\section{International Journal of Pulmonary \& Respiratory Sciences}

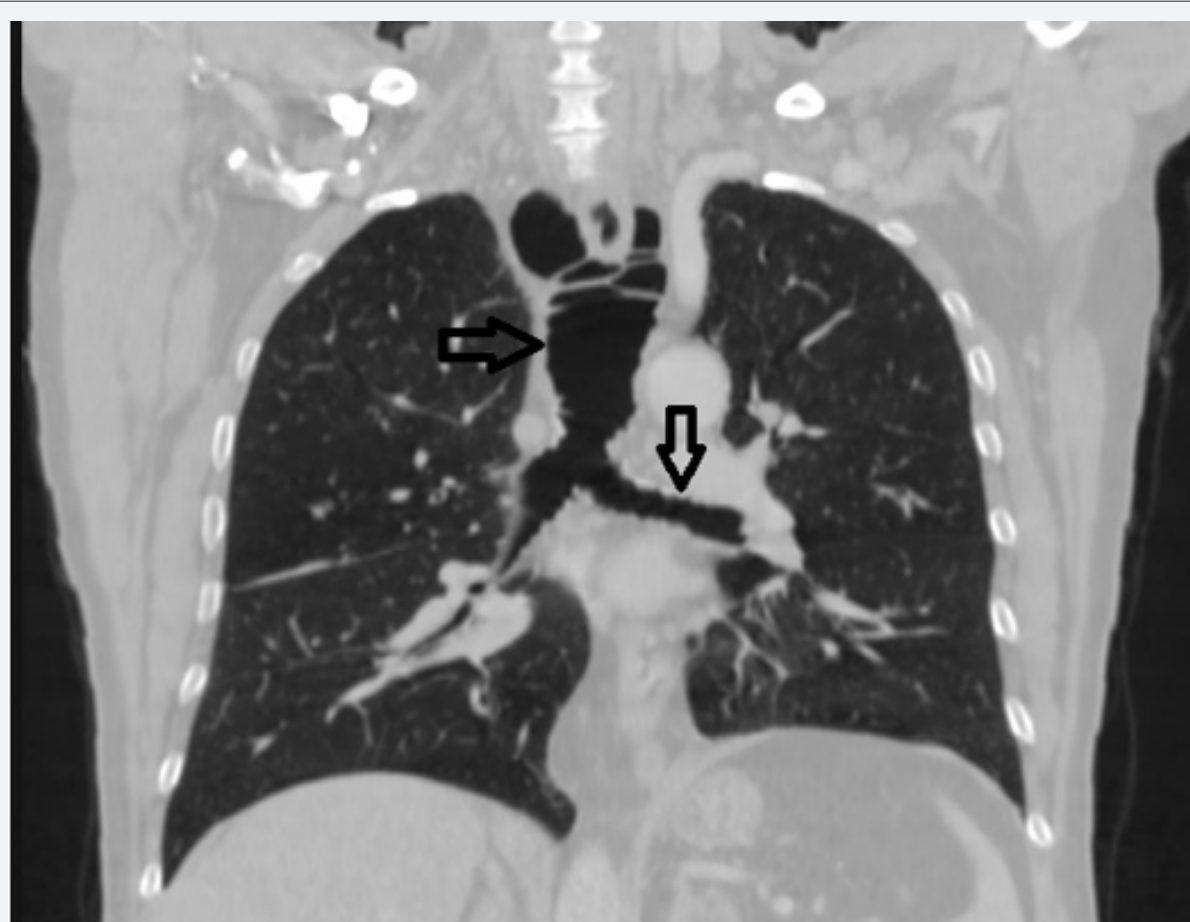

Figure 4: CT image reconstruction confirming Mounier Kuhn's syndrome.

Bronchial fibroscopy demonstrated an inflammatory aspect of the mucosa with tracheomalacia and tracheal diverticulum (Figure 5). Spirometry was suggestive of obstructive abnormality with poor bronchodilator reversibility, Alpha-1 antitrypsin was $255 \mathrm{mg} / \mathrm{dL}(100-300 \mathrm{mg} / \mathrm{dL})$, nasal endoscopy did not reveal any polyposis and the spermogram was not performed (patient, father of 7 children). The diagnosis of a Mounier Kuhn syndrome has been made. The evolution under antibiotic treatment (of the episode of infection) and adequate chest physiotherapy for postural drainage of secretions was marked by clinical and biological improvement.

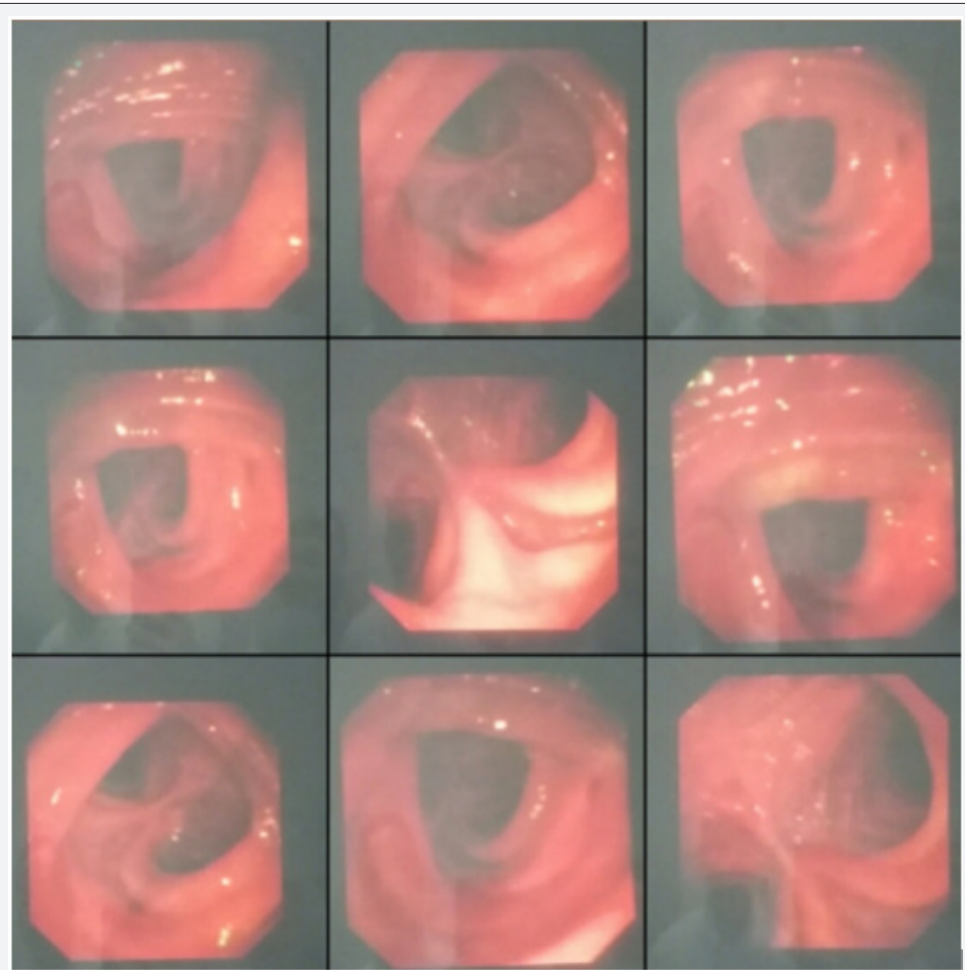

Figure 5: Endoscopic appearance of tracheomalacia and tracheal diverticulum. 


\section{Discussion}

Mounier Kuhn syndrome is a rare congenital disorder. It is characterised by a developmental defect in the connective tissue and smooth muscle resulting in increased tracheal diameter and enlarged main bronchi. There is also an absence of the myenteric plexus of the bronchial tree. Diagnosis usually takes place in adulthood. No correlation between increasing age and increasing tracheal diameter was found [2].

The syndrome was first described by Mounier Kuhn in 1932 and the term tracheobronchomegaly was introduced by Katz and al. in 1962. The mechanism is not known. It is a rare disease that can come in congenital form: familial forms were described with possible recessive inheritance, or in acquired form: Pulmonary fibrosis in adults and after mechanical ventilation in premature babies (Barotrauma). Some patients develop mucosal herniation between the tracheal rings leading to tracheal diverticulosis. The poor clearance of secretions is associated with recurrent lower respiratory tract infections [3]. There is also increase in dead space and tidal volume [4].

This syndrome predominates in humans in the third and fourth decade [5]. Our presentation is that of a 53-year-old patient. The symptomatology is non-specific, poor or absent and is manifested basically by recurrent bronchopulmonary infections [6] and it is the same clinical symptomatology reported in our observation. The clinical examination can be strictly normal, as it can show nasosinus polyposis and a polymalformative syndrome with bilateral ptosis, epicanthus, micrognathia and excess skin of the upper lip. Our patient presents only bilateral ptosis. Asthenospermia or azoospermia has been reported in some patients with Mounier-Kuhn syndrome. Chest X-ray can help diagnosis by showing an increase in the size of the trachea beyond $3 \mathrm{~cm}$ especially in profile incidence [7].

Thoracic computed tomography confirms the diagnosis, it finds an increase in the tracheal transverse diameter upper than $3 \mathrm{~cm}$ in adults, and an increase in the right and left main bronchi greater than à $2.4 \mathrm{~cm}$ et $2.3 \mathrm{~cm}$ respectively. It also serves to reveal cylindrical or cystic proximal bronchiectasis, extending to the fourth-order bronchi. The distal bronchial tree is usually normal. Magnetic Resonance Imaging (MRI) does not have any supplementary advantage in diagnosis [7].

Bronchoscopy may show dilated proximal airways with purulent secretions, tracheal diverticula and tracheomalacia. Recent data would suggest that bronchoscopy with confocal microscopy may aid diagnosis by permitting real-time analysis of the bronchial mucosal microstructure, demonstrating a deficiency of elastin fibres within the bronchial wall. Bronchoscopy can be difficult to perform because of important airway obstruction due to tracheomalacia [7].

Spirometry can show different degrees of obstruction or increased residual function [7]. Meunier-Kuhn syndrome has 3 subtypes. In type 1 , there is a slight symmetric dilation in the trachea and main bronchi. In type 2, the dilation and diverticula are distinct. In type 3 , diverticular and saccular structures extend to the distal bronchi [8]. Our patient is classed in type 2 .

Literature reviews have discussed the possibility of associating Meunier Kuhn's syndrome with other congenital pathologies such as Kenny-Caffey syndrome, Maran's syndrome, hypogammaglobulinemia, Ataxia-telangiectasia, Ankylosing spondylitis, Brachman-de Lange syndrome and cutis lax $[8,9]$. This association makes the understanding of the mechanism of the occurrence of Meunier Kuhn syndrome more complicated. Most frequent pulmonary complications are bullous emphysema, aspergillosis and pneumothorax $[7,10]$. Our patient has a Meunier Kuhn syndrome without any other association or complication.

The main differential diagnosis in our observation is WilliamsCampbell syndrome which is a rare condition characterized by the absence of cartilaginous rings in the sub segmental bronchi, resulting in dilation of the cystic bilateral bronchi which collapse on expiration and induce a hyperinflation. It usually affects the bronchi beyond third division (fourth to sixth order) [11]. The caliber of the trachea and main bronchi is strictly normal: this concept is fundamental; it characterizes the Williams Campbell syndrome and allows to exclude this diagnosis in our observation.

Treatment is based on physiotherapy and appropriate antibiotic therapy in case of outbreak Infection (which is often the result of atypical organisms, tuberculous or non-tuberculous mycobacteria). Prevention of recurrent infections will prevent progression to irreversible pulmonary fibrosis [12]. Central impairment excludes any surgical treatment, and the placement of tracheobronchial prosthesis was reported in advanced cases. Lung transplantation has been performed in at least two cases of Mounier-Kuhn syndrome, one of who unfortunately died in the post-operative period.

\section{Conclusion}

Mounier-Kuhn syndrome or tracheobronchomegaly is a very rare condition who's congenital or acquired origin is still controversial. The clinical signs are not very specific and; it should be kept as a differential diagnosis in patients coming with recurrent lower respiratory tract infections. The radiological diagnosis is easy, based on a careful analysis of the central airways and pulmonary parenchyma by CT examination. However, more work must be done in terms of treatment and follow up of this orphan disease.

\section{Consent}

Written informed consent was obtained from the patient for publication of this case report and any accompanying images.

\section{Conflicts of Interest}

There are no conflicts of interest between the authors and between the authors and the patient. 


\section{Disclosure}

This case report was written based on clinical observation without any funding.

\section{Authors' Contributions}

Fatima Zahra Mrabet drafted this manuscript under Hicham Souhi's supervision. Jihane Achrane, Hanane Ouazzani, Ismail Rhorfi and Ahmed Abid have made substantial contributions to acquisition of data.

\section{References}

1. Sarita Kumari (2016) A Case of Mounier-Kuhn Syndrome. India Journal of Advances in Medicine (JAM) 5(1): 19-20

2. Ghewade B, Ali S, Chaudhari S, Cladius S (2015) Tracheobronchomegaly: A Rare Cause of Bilateral Bronchiectasis. National Journal of Medical Research print 5(4): 325-328.

3. Deka N, Hazarika M, Goswami G (2015) Mounier Kuhn syndrome in adult: a case report. International Journal of Research in Medical Sciences 3(4): 987-989.

4. Kavcic P (2015) Clinical and Radiological Manifestations of Congenita Tracheobronchomegaly (Mounier - Kuhn Sydrome). J J Pulmonol 1(1): pp. 001.
5. Cicekci F (2016) Development of Tracheobronchomegaly during Mechanical Ventilation: An Unusual, Case Report. Anadolu Klin/Anatol Clin 21(1): 76-79.

6. Suhas HS, Utpat K (2017) Rare association of Mounier-Kuhn syndrome with panlobular emphysema. JEBMH 4(52): 3212-3213.

7. Quentin C, Lefevre N, Bodart E, Hanssens L (2018) Mounier Kuhn Syndrome Presenting with Recurrent Atelectasis. Acta Clin Belg 73(3): 233-235.

8. Tanay J, Ashwin S, Shibani V, Bhupendra C, Ekjot G, et al. (2016) A rare case of Mounier-Kuhn syndrome with bronchial asthma. Int J Med Res Health Sci 5(7): 105-108.

9. Ashfaq Ul Hassan, Shifan Khanday, Muneeb Ul, Zahida Rasool (2015) The Rare Case of Monier Kuhn Syndrome or the Tracheobronchomegaly Syndrome. Med Res 2(1): 01-04.

10. Akgedik R, Dağlı CE, Kurt AB, Öztürk H, Taș N (2016) The association of Mounier-Kuhn Syndrome and pulmonary aspergillomas: A case report. Balkan Med J 33(5): 585-586.

11. Mitra S, Chowdhury AR, Bandyopadhyay G (2015) Williams-Campbell Syndrome-A Rare Entity of Congenital Bronchiectasis: A Case Report in Adult. Int J Med Res Health Sci 4(4): 913-915.

12. Fletcher A, Stowell J, Jamoulis S (2017) Congenital Tracheobronchomegaly (Mounier-Kuhn Syndrome) in a Woman with Human Immunodeficiency Virus: A Case Report. Cureus 9(4): e1136.

Your next submission with Juniper Publishers will reach you the below assets

- Quality Editorial service

- Swift Peer Review

- Reprints availability

- E-prints Service

- Manuscript Podcast for convenient understanding

- Global attainment for your research

- Manuscript accessibility in different formats

( Pdf, E-pub, Full Text, Audio)

- Unceasing customer service

Track the below URL for one-step submission https://juniperpublishers.com/online-submission.php 